\title{
The Effect of Sense of Coherence on Mental Health Outcomes Moderating Role of Positive Psychological Capitals: A Cross Cultural Study
}

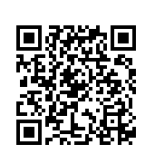

\author{
Saeed Anwar*, Omer Farooq, Qaiser Arshad, Anam Khan and Asmat Kakar \\ Department of Psychology International Islamic University Islamabad, Pakistan
}

Submission: May 02, 2019; Published: May 24, 2019

*Corresponding author: Saeed Anwar, Department of Psychology International Islamic University Islamabad, Pakistan

\begin{abstract}
The current study examined the effect of sense of coherence on mental health outcomes moderating role of positive psychological capitals: a cross-cultural study. Sample collected from $(N=271)$ Chinese and Pakistani participants through purposive convenient sampling technique. Sense of coherence positive psychological capitals and depression anxiety and stress scale was used to measure the Sense of coherence developed by (lovi bond and Short Warwick Edinburgh). Well-being Questionnaire was used to collect the data regarding study variables. The results have shown that the stress negatively and Positive psychological capitals positively predicts well-being among Chinese and Pakistani students. Results revealed that stress negatively predicts well-being. This study examined sense of coherence with its three dimensions known as meaningfulness, manageability and comprehensiveness, and the findings are in line with the pervious literatures.
\end{abstract}

Keywords: Sense of Coherence; Positive psychological capital; Wellbeing; Stress

\section{Introduction}

Cultural diversity plays a vital role in the wellbeing of the individuals. Therefore, we have to consider that what are the underlying causes of well-being and what factors enhances the level of wellbeing? Which type of personality traits causes wellbeing? This study will enlighten us about individuals of different cultures having respective traits effects the wellbeing.

Well-being is associated to individual life satisfaction and positive feelings toward living standards [1,2]. Furthermore, with other people it contained of positive connection, determination in life \& coping strategy. Cultural stability and its effects also associated with Well-being [3].

American Psychological Associations (2008), Stress is the response of individual while facing imminent threat and sense danger. Constant Stress creates uncertainty in the life of a man. D'Zurillo (1990) demonstrated as stress concept associated with wellbeing. Lovallo (2005) stress factor is provocation that arouses health factor.Sense of coherence has huge outcomes of mental health as [4] mentioned that how people manage stress and stay well. He observed in studies that stress is pervasive, but not all individuals have negative health outcomes in response to stress. Instead, some people achieve health despite their vulnerability to potentially restricting stress factors.
Luthans et al. [5] define positive psychological capital as: psychological state of individual having self-efficacy, optimism, hope and resiliency. It shows the attribute of the individual having heroism within. A person's optimistic developmental state which comprehend by four higher order of capabilities which are self-confidence acquired for success, expecting something good to be happened, tackling difficulties with sheer will, belief of achieving something which individual wants $[5,6]$. The factors of positive psychological capital play a keen role in facing the tense situation at workplace [6]. These factors are directly proportional to the wellbeing of the individual [7].

\section{Methodology}

The current study was based on cross-sectional survey research and designed to examine the moderating role of Positive Psychological Capital between sense of coherence and mental wellbeing in nuclear and joint families living in Pakistan and China.

\section{Participants}

Participants were recruited from range of universities and colleges within Pakistan and China. Ethical approval was obtained from the Ethical Committee Department of Psychology. Further, permission was taken for data collection from the 
relevant authorities of institutions. Individuals were excluded if they are unwilling or unable to give informed consent. 600 individuals were approached and requested to participate in the study, 23 refused to participate and 56 didn't replied at all, resulting 521 study participants. The sample comprised of males $(\mathrm{n}=334 ; 64.1 \%)$ and females $(\mathrm{n}=187 ; 35.9 \%)$. Participants from Pakistan $(n=335 ; 64.3 \%)$ and China $(n=186 ; 35.7 \%)$. A large proportion of sample was from Joint family system $(n=232$; $44.5 \%)$ as compare to Nuclear $(n=232 ; 44.5 \%)$. Participants in study from high socio economic status were $(n=139 ; 26.7 \%)$ from middle $(n=295 ; 56.6 \%)$ and from lower socio economic class were $(n=87 ; 16.7 \%)$. Informed consent along with the booklet containing psychometric instruments and demographic sheet were provided. Participants filled the booklet in the presence of the researcher.

\section{Instrumentation}

\section{Positive psychological capital (PPC)}

To measure PPC, scale used was PPCQ-24 (the validity of result can be found in Luthans, Avolio, et al., 2007, and Luthans, Youssef, and Avolio, 2007, comprises the whole Positive psychological capital 24 items and free for each- mission for study of research purpose can be acquired from (www.mindgarden.com). Positive psychological capital is a higher order concept, comprising of 4 subscales, containing 6 items each for an aggregate of 24 things. The subscales incorporate Optimism, Hope, Self-efficacy and Resilience. Total items were measured utilizing a 6-point Lik-ert size of questionnaire 1 strongly disagree to 6 strongly agree. The questionnaire items drawn from built up scales already distributed and tried. They each have been utilized as a part of other late working environment [5] and the Positive psychological capital -24 in general, Avey, Wernsing and Luthans (2008) Luthans, Avolio et al. (2007); Luthans et al. (2008). Alpha reliability for PPCQ is .90 .

\section{Sense of Coherence Scale (SOCS)}

Short version of SOCS [4] was used to measure sense of coherence comprising of 13-items initially derived from 29item Orientation to Life Questionnaire that is based upon the cognitive, behavioral and motivational mechanisms of SOC theory including meaningfulness, comprehensibility and manageability. The score for each item ranged from 1 (showing weak) to 7 (showing strong) with four items have reverse scoring. Total scores have been calculated by summing up the raw scores. The score ranged from 91 as extreme to 13 as least. low score indicates a low position on the SOC continuum, and high score indicates a high level of SOC. Test-retest reliability of this scale ranged from .69 to .78 and Alpha coefficient ranged from.70 to. 92 .

\section{Warwick Edinburg Mental Well-Being Scale}

Warwick Edinburg Mental Well-Being Scale developed by Tennant et al. (2007) a Short version, was used and it contains 7 items with 5 categories, it is designed to measure both feeling and functioning aspects of positive mental well-being specifically. Response options could be assigned along 7-point Likert scale from 1 to 7 and possible scores ranged from 7 to 35 . There are no cut off scores as it is not designed to identify individuals with exceptionally low or high on positive mental health.

\section{Depression Anxiety Stress Scale (DASS-21)}

A Stress Subscale of short version of DASS was used to estimate stress among students. This inventory was established by Lovibond and Lovibond (1995) and overall scale was comprised of 21 items and 7 items for each three subscales including depression, anxiety and stress. Stress Subscale was a 4-point Likert-type scale and response options ranged from 0 (did not apply at all over the past week) to 3 (applied very much over the last week) and possible scores ranged from 0 to 28 . In the present study, low and high scores were used to measure stress among students.

\section{Results}

Similarly, individuals living in joint families scored $(\mathrm{M}=$ $82.95, \mathrm{SD}=18.70$ ) higher on PPC as compared to individuals living in nuclear families ( $M=71.09, \mathrm{SD}=18.32)$. The observed difference was not significant as $\mathrm{t}(521)=3.71, \mathrm{p}>.05$. Socio Economic status was associated with statistical differences in relation to SOC Wellbeing PPC and stress, with SOC Wellbeing PPC at increased rates among individuals from higher economic class, and decreased rates among individuals from lower socio economic class, and Stress is more common among individuals from lower socio economic class (Table 1).

Table 1: Socio Economic Class Association with Positive Psychological Capital, Wellbeing, Stress and Sense of Coherence and Stress.

\begin{tabular}{|c|c|c|c|}
\hline Measures & Mean (SD), 95\% CI & Statistics F, p & Post-Hoc Analysis \\
\hline PPC & & \multirow{2}{*}{$359.15, \mathrm{p}<.00$} & High $>$ Middle $>$ Low, $\mathrm{p}<.01$ \\
\hline Low & $56.56(9.96), 54.54-58.68$ & & \\
\hline Middle & $73.34(11.15), 72.07-74.62$ & & \multirow{2}{*}{ High $>$ Middle $>$ Low, $\mathrm{p}<.01$} \\
\hline High & $100.07(16.40), 97.32-102.83$ & & \\
\hline Wellbeing & & & \\
\hline Low & $12.56(4.28), 11.64-13.47$ & & \\
\hline Middle & $17.22(4.18), 16.74-17.70$ & & \\
\hline
\end{tabular}




\section{Psychology and Behavioral Science International Journal}

\begin{tabular}{|c|c|c|c|}
\hline Stress & & \multirow{4}{*}{$112.12, \mathrm{p}<.00$} & \multirow{4}{*}{ Low $>$ Middle $>$ High, $p<.01$} \\
\hline Low & $20.62(4.10), 19.74-21.49$ & & \\
\hline Middle & $15.79(4.22), 15.31-16.27$ & & \\
\hline High & $12.75(2.63), 12.31-13.19$ & & \\
\hline SOC & & \multirow{4}{*}{$337.52, \mathrm{p}<.00$} & \multirow{4}{*}{ High $>$ Middle $>$ Low, $\mathrm{p}<.01$} \\
\hline Low & 30.65 (5.41), $29.50-31.80$ & & \\
\hline Middle & $42.25(8.05), 41.33-43.17$ & & \\
\hline High & $61.30(12.66), 59.17-63.42$ & & \\
\hline
\end{tabular}

Note: PPC Positive Psychological Capital; SOC Sense of Coherence.

In overall sample Pearson correlation among study variables Outcomes stipulate that PPC has significant positive correlation with Wellbeing $(\mathrm{r}=.53, \mathrm{p}<.001)$ and SOC $(\mathrm{r}=.76, \mathrm{p}<.001)$ but negatively Correlated with Stress $(r=-.47, \mathrm{p}<.001)$. Wellbeing is negatively Correlated with Stress $(r=-.58, p<.001)$ and positively with SOC $(r=.54, \mathrm{p}<.001)$. Stress is negatively correlated with SOC $(r=-.49, \mathrm{p}<.001)$. Same trend is seen in Pakistani and Chinese Individuals, PPC, SOC and Wellbeing Are Positively Correlated with each other but negatively correlated with Stress (Table 2).

Table 2: Correlation between Measures under Investigation.

\begin{tabular}{|c|c|c|c|c|}
\hline & 1 & 2 & 3 & 4 \\
\hline Variables & \multicolumn{4}{|c|}{ Total Sample $(\mathrm{N}=521)$} \\
\hline 1. PPC & 1 & $.53^{* * *}$ & $-.47^{* * *}$ & $.76^{* * *}$ \\
\hline 2. Wellbeing & & 1 & $-.58 * * *$ & $.54 * * *$ \\
\hline 3. Stress & & & 1 & $-.49^{* * *}$ \\
\hline \multirow[t]{2}{*}{ 4. SOC } & & & & 1 \\
\hline & \multicolumn{4}{|c|}{ Pakistan $(\mathrm{n}=2)$} \\
\hline 1. PPC & 1 & $0.37^{* * *}$ & $-0.46^{* * *}$ & $0.74^{* * *}$ \\
\hline 2. Wellbeing & & 1 & $-.53^{* * *}$ & $.36^{* * *}$ \\
\hline 3. Stress & & & 1 & $-.49^{* * *}$ \\
\hline \multirow[t]{2}{*}{ 4. SOC } & & & & 1 \\
\hline & \multicolumn{4}{|c|}{ China $(\mathrm{n}=18)$} \\
\hline 1. PPC & 1 & $.63^{* * *}$ & $-.49 * * *$ & $.71^{* * *}$ \\
\hline 2. Wellbeing & & 1 & $-.67^{* * *}$ & $.62 * * *$ \\
\hline 3. Stress & & & 1 & $-.58^{* * *}$ \\
\hline 4. SOC & & & & 1 \\
\hline
\end{tabular}

Note: PPC Positive Psychological Capital; SOC Sense of Coherence; ${ }^{* * *} \mathrm{p}<0.001$

Moderation analysis produced that PPC influenced SOC vicariously through its effect on wellbeing. It specifies that moderation occurs owing to extremely significant interaction effect, $\mathrm{b}=.001,95 \%$ CI $[.0005, .002], \mathrm{t}=2.88, \mathrm{p}<.01$, indicating that relationship between Sense of Coherence and Wellbeing is moderated by Positive Psychological Capital (Table 3).

Table 3: Conditional effect of SOC on Wellbeing at different values of PPC.

\begin{tabular}{|c|c|c|c|c|}
\hline Values of PPC & Effects of SOC on Wellbeing (b) & S.E & $\boldsymbol{t}$ & $\boldsymbol{P}$ \\
\hline$-19.43(-1$ SD) & $.08[0.03,0.14]$ & .03 & 3.13 & $\mathrm{p}<.01$ \\
\hline $.00(\mathrm{M})$ & $0.12[0.07,0.15]$ & .02 & 5.70 & $\mathrm{p}<.001$ \\
\hline $19.43(+1$ SD) & $0.15[0.11,0.18]$ & 0.01 & 7.93 & $\mathrm{p}<.001$ \\
\hline
\end{tabular}

Note: PPC Positive Psychological Capital; SOC Sense of Coherence.

\section{Discussion}

In this cross-cultural study, the association of SOC with PPC on Wellbeing, Stress and range of demographics has been examined in the large sample of students in Pakistan and China.
Additionally, due to so much collaboration of Pak-China in every aspect of life these days this study examining the moderating role of PPC between SOC and Wellbeing, and also looking at students from two different cultures that how they are scoring 
on these variables. All the hypotheses were tested by employing moderated regression analysis.

Initial hypothesis of current research is supported by the findings indicating that $\mathrm{SOC}$ in total sample as well as separately, in both Pakistani and Chinese Culture is a significant forecaster or predictor of well-being. These results are reliable and strengthening the previous evidences that suggest sense of coherence contributes well-being [4,7]. Like many previous studies also suggest that sense of coherence is an excellent predictor of well-being and upsurges the person's managing options to cope with stressful circumstances in a healthier way [8-10].

\section{Sense of Coherence Theory projected by Antonovsky}

Antonovsky [4] shows that SOC denotes to a person's capability to efficiently manage life stressors and the aptitude to increase level of wellbeing. The present results inveterate the theory under examination. According to Second hypothesis results established indirect \& direct consequence on growing well-being and dropping stress, of sense of coherence. Moreover, besides sense of coherence, Positive Psychological Capital is also anticipated as a predictive factor for well-being. This hypothesis also receives support in the present study. The factors of positive psychological capital play a keen role in facing the tense situation at workplace [6]. These factors are directly proportional to the wellbeing of the individual [3]. Third hypothesis under study also proved according to findings as previous studies suggest regarding nuclear and joint family systems. If individuals getting support from their close relationship (as there is a network of friends and significant others) enjoy good mental health Specified by Ryan et al. [11]. Investigators investigates and then claimed that need for social affiliation is essential feature in human life as human beings are social animals and they are incapable to spend better life deprived of social networks [12] and these social relationships are essential to maintain psychological well-being [12-15].

Both PPC and SOC are positively correlated with wellbeing, Pallant \& Lae (2002); Forgeard \& Seligman, (2012). Recently (Julian) investigated that individuals which had high SOC and PPC showed enhanced level of servant leadership and had decreased level of leadership stress. In addition, our hypothesis confirmed by results that PPC moderating the effect of SOC on wellbeing, which is positive and significant. For endorsing this point, a cross cultural research has been conducted in Pakistan which shows that the relationship between sense of coherence and mental health outcomes in collectivistic culture and individualistic culture moderated by social support (Naveed) [16-18].

\section{Limitations and Suggestions}

Present study established some limitations. First, the main issue which is encountered was the language, as both countries native language is non-English. Pakistani individual's native language is Urdu, and individuals of China speak Chinese. Therefore, in data collection hurdles were experienced. Secondly samples which is collected from both countries was universities students so it can be generalized to the whole population. Lastly, a common method variance may also influence the findings; while, cross-sectional designs usually have low internal validity, thus triangulation could be more appropriate. For future researches translation and validation of the scales according to the culture native language can be helpful to accumulate the more authentic data from the participants. Ultimately, it would be more important to study other nations which have not yet been searched on the construct of sense of coherence.

\section{References}

1. Diener E, Oishi S, Lucas RE (2003) Personality, culture, and subjective wellbeing: Emotional and cognitive evaluations of life. Annu Rev Psychol 54: 403-425.

2. Diener E (1984) Subjective well-being. Psychological Bulletin 95(3): 542-575.

3. Diener E, Suh EM, Lucas RE, Smith HL (1999) Subjective well-being: Three decades of progress. Psychological Bulletin 125(2): 276-302.

4. Antonovksy, A (1987) Unrevealing the mystery of health: How people manage stress and stay well. Jossey-Bas: San Francisco, California, USA.

5. Luthans F, Youssef CM (2007) Emerging positive organizational behavior. Journal of Management 33(3).

6. Luthans F, Youssef CM (2004) Human, Social, and Now Positive Psychological, Capital Management: Investing in people for competitive advantage. Organizational Dynamics 33(2): 143-160.

7. Rothmann S (2003) Burnout and engagement: A South African perspective. SA Journal of Industrial Psychology 29(4): 16-25.

8. Bezuidenhout A, Cilliers (2010) Burnout, work engagement, and sense of coherence in female academics in higher-education institutions in South Africa. SA Journal of Industrial Psychology 36(1): 110- 157.

9. Rothmann S, Jackson LTB, Kruger MM (2003) Burnout and job stress in a local government: The moderating effect of sense of coherence. South African Journal of Industrial Psychology 29(4): 52-60.

10. Rothman S, Steyn LJ, Mostert K (2005) Job stress, sense of coherence and work wellness in an electricity supply organization. South African Journal of Business Management 36: 19-30.

11. Ryan RM, Kalil A, Leininger L (2009) Low-income mothers' private safety nets and children' socio-emotional well-being. Journal of Marriage and Family 71: 278-297.

12. Berkman LF, Glass T, Brissette I, Seeman TE (2000) From social integration to health: Durkheim in the new millennium. Soc Sci Med 51: 843-857.

13. Berkman LF (1995) The role of social relations in health promotion. Psychosom Med 57: 245-254.

14. Luthans $F$ (2002) The need for and meaning of positive organizational behavior. J Orgn Behav 23(6): 695-706.

15. Luthans F, Jensen SM (2002) Hope: A new positive strength for human resource. Human Resource Development Review 1(3).

16. Luthans F, Avey JB, Avolio BJ, Peterson SJ (2010) The development and resulting performance impact of positive psychological capital. Human Resource Development Quarterly 21(1): 41-67. 
17. Lyubomirsky S, King L, Diener E (2005) The benefits of frequent positive affect: Does happiness lead to success? Psychol Bull 131: 803855

18. Reis HT, Collins N (2000) Measuring relationship properties and interactions relevant to social support. In: S Cohen, LG Underwood, BH

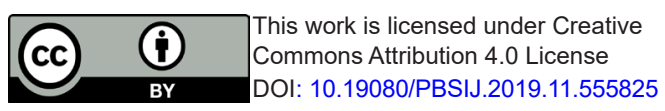

Gottlieb (Eds.), Social support measurement and intervention: A guide for health and social scientists Oxford University Press: New York, USA: pp. 136-192.

\section{Your next submission with Juniper Publishers will reach you the below assets}

- Quality Editorial service

- Swift Peer Review

- Reprints availability

- E-prints Service

- Manuscript Podcast for convenient understanding

- Global attainment for your research

- Manuscript accessibility in different formats

( Pdf, E-pub, Full Text, Audio)

- Unceasing customer service

Track the below URL for one-step submission https://juniperpublishers.com/online-submission.php 